\title{
IMPLANT-ASSOCIATED PATHOLOGY: AN ALGORITHM FOR IDENTIFYING PARTICLES IN HISTOPATHOLOGIC SYNOVIALIS/SLIM DIAGNOSTICS
}

\author{
V. Krenn ${ }^{1}$, P. Thomas 2 , M. Thomsen ${ }^{3}$, S. Usbeck ${ }^{4}$, L. Scheuber ${ }^{4}$, F. Boettner ${ }^{5}$, W. Rüther ${ }^{6}$, F. Hopf ${ }^{1}$, \\ S. Müller ${ }^{1}$, M.G. Krukemeyer ${ }^{7}$, T. Gehrke ${ }^{8}$, D. Kendoff ${ }^{8}$, A. Tiemann ${ }^{9}$, M. Huber ${ }^{10}$ \\ ${ }^{1}$ Center for Histology, Cytology and Molecular Diagnostics, Trier \\ ${ }^{2}$ Hospital and Outpatients' Clinic for Dermatology and Allergology, Ludwig Maximilian University, Munich \\ ${ }^{3}$ DRK Hospital, Orthopedics and Trauma Surgery, Baden-Baden \\ ${ }^{4}$ CeramTec GmbH, Science Department, Plochingen \\ ${ }^{5}$ Hospital for Special Surgery/HSS, New York City, New York, USA \\ ${ }^{6}$ Department of Orthopaedics University Medical Center Hamburg Eppendorf \\ ${ }^{7}$ Paracelsus-Kliniken Deutschland Gmbh, Osnabrück \\ ${ }^{8}$ HELIOS ENDO-Klinik, Hamburg \\ ${ }_{9}^{S R H}$ Zentralklinikum Suhl, Klinik für Orthopädie und Unfallchirurgie, Suhl \\ ${ }^{10}$ Institute of Pathology and Bacteriology, Otto Wagner Hospital, Vienna, Austria
}

In histopathologic SLIM diagnostic (synovial-like interface membrane, SLIM) apart from diagnosing periprosthetic infection particle identification has an important role to play. The differences in particle pathogenesis and variability of materials in endoprosthetics explain the particle heterogeneity that hampers the diagnostic identification of particles. For this reason, a histopathological particle algorithm has been developed. With minimal methodical complexity this histopathological particle algorithm offers a guide to prosthesis material-particle identification. Light microscopic-morphological as well as enzymehistochemical characteristics and polarization-optical proporties have set and particles are defined by size (microparticles, macroparticles and supra- macroparticles) and definitely characterized in accordance with a dichotomous principle. Based on these criteria, identification and validation of the particles was carried out in 120 joint endoprosthesis pathological cases. A histopathological particle score (HPS) is proposed that summarizes the most important information for the orthopedist, material scientist and histopathologist concerning particle identification in the SLIM.

Key words: synovial-like interface membrane (SLIM), particle algorithm, prosthesis dysfunction, wear particles, adverse reactions, toxic reaction.

\section{ПАТОЛОГИЯ, ВЫЗВАННАЯ ИМПЛАНТАТОМ: АЛГОРИТМ ОПРЕДЕЛЕНИЯ ЧАСТИЦ ПРИ ГИСТОПАТОЛОГИЧЕСКОМ ИССЛЕДОВАНИИ СИНОВИАЛЬНО-ПОДОБНОЙ ОКОЛОПРОТЕЗНОЙ МЕМБРАНЫ (SLIM)}

\author{
В. Кренн, П. Томас, М. Томсен, С. Усбек, Л. Шойбер, Ф. Боттнэр, В. Рютер, Ф. Хопф,
} С. Мюллер, М.Г. Крукемейер, Т. Герке, Д. Кендофф, А. Тиманн, М. Хубер

Важную роль при гистопатологическом исследовании синовиально-подобной околопротезной мембраны (SLIM), наряду с диагностикой околопротезной инфекции, играет идентификация частиц. Различия в патогенезе частиц и разнообразии материалов для эндопротезирования объясняют ту гетерогенность, которая затрудняет диагностическую идентификацию частиц. По этой причине был разработан гистопатологический алгоритм диагностики частиц, который при минимальных методологических сложностях обеспечивает идентификацию частиц материала протеза. Простые микроскопически-морфологические и энзим-гистохимические характеристики, а также поляризационно-оптические свойства позволяют определить размер частиц (микрочастицы, макрочастицы и супер-макрочастицы) и характеризовать их по дихотомическому принципу. На основании этих критериев были выполнены идентификация и аттестация частиц в 120 случаях патологической реакции на эндопротез сустава. Предложена гистопатологическая шкала частиц (HPS), которая суммирует важнейшую информацию для ортопедов, материаловедов и гистопатологов, касающуюся идентификации частиц методом SLIM.

Ключевые слова: синовиально-подобная интерфейс-мембрана (SLIM), алгоритм частиц, дисфункция протеза, износ частиц, побочные реакции, токсические реакции. 


\section{Introduction}

Since endoprosthesis pathologies are moving more into the diagnostic histopathology, diagnostic criteria and algorithm especially for particle identification gain in importance. Pathologists, material scientists and orthopedic surgeons find themselves confronted with the problem of particle heterogeneity and that increasing numbers of implantations during arthroplasty interventions are being accompanied by a rising number of implant failures due to complications. Extraneous materials and/or corrosion phenomena of implant materials are being discussed as the cause of immunopathological/inflammatory reactions and toxicity reactions. The term "adverse reaction to metal debris" (ARMD) is used to clarify the range of undesirable clinical outcomes especially due to metal ion and particle exposure. Corrosion products of cobalt-chromium-molybdenum alloys, metal wear particles and metal ions can, depending on their concentrations, trigger a toxic, immunological or inflammatoric reaction $[12,18,24,31,50,51$, 52]. A sufficient clarification of endoprosthesis pathologies in the interdisciplinary context requires biomechanical, clinical [3], microbiological [33, 38], allergological and radiological/imaging findings [7] a macroscopic assessment of the explants and especially a histopathological diagnosis based on defined diagnostic criteria with high reproducibility. From the histopathologist a definite morphological diagnosis with clarification of the pathogenesis is expected, the orthopedic surgeon expects guidance and support where complex diagnostic and therapeutic problems are concerned, for instance when implant material allergy or a toxicity reaction on implant material are clinically suspected.

\section{The objective}

The histopathological particle algorithm after Krenn is based on these considerations allowing a definite histopathological particle characterization in the SLIM ("synovial-like interface membrane", SLIM) and is designed to lead to a better interpretation of implant-tissue interaction, in order to facilitate a more comprehensive understanding of particle induced endoprosthesis pathologies. Consequently, the differential diagnosis and the identification of particulate, crystalline and noncrystalline components is crucial $[7,28,30,35$, 41, $42,43]$. This applies in particular to the differential diagnostics of the neosynovial/periprosthetic membrane SLIM in which particle identification and characterization is required. This is because particleinduced reactions in the SLIM may constitute a fundamental cause of implant failure $[2,8,16,50,53$, $59,60]$. The differences in implant materials and their wear particles, the diversity of particle origin $[2,3,6$,
$8,14,50,53,59]$ and the high degree of variability of the immune and inflammatory response explain the morphological heterogeneity of wear particles in the synovial membrane/SLIM that, in turn, hampers definitive particle identification. For these reasons, a histopathological particle algorithm (Diagram 1) has been developed that, with minimal methodical complexity, facilitates particle identification in the synovial membrane/SLIM and especially allows the demarcation between non-prosthesis material particles and prosthesis material particles.

This histopathological particle algorithm had been published as a proposal focusing on the differential diagnosis to endogenous particles, in the context of implant material allergies and in a validated form based on 105 joint pathology cases $[28,29,30]$. In this study the number of cases is enlarged and particle types which have not been shown before are demonstrated in this paper. Additionally a new definition of particle-size is proposed: microparticles, macroparticles and supra-macroparticles.

\section{Material and methods}

The majority of particle types have been defined and had been shown microscopically and are based mainly on particle criteria described in animal models and from biomechanical experiments [7, 8, 9, 19, 20, 22, 23, 24, 32, 34, 35, 36, 60] But, as the latter were detected and validated in 120 defined synovitis/SLIM cases and thus also validated and new particle characteristics have been described and recognised, they are shown in the results section.

\section{Patients and methods}

Morphological and enzyme-histochemistrical particle criteria for the algorithm. The histopathologic particle algorithm is based on the light microscopic and histochemical characteristics for particle identification described in the literature $[7,8,9,19,20,22,23,24,32,34,35,36,60]$. Three basic criteria were defined: light microscopicmorphological characteristics (size, shape, color, dissolved out), polarization-optical properties, enzyme-histochemical characteristics in oil red $\mathrm{O}$ staining [20] and the Prussian blue reaction. The particles are characterized in accordance with a dichotomous principle, based on the staining characteristics in the Prussian blue reaction, in oil red $\mathrm{O}$ staining, the size and the polarizationoptical characteristics. This has been illustrated graphically in the form of a flow chart (Diagram 1). The SLIM diagnostic and particle characterization including identification of corrosion products was carried out by two experienced pathologists specialising in orthopedic pathology (M. Huber and V. Krenn). 


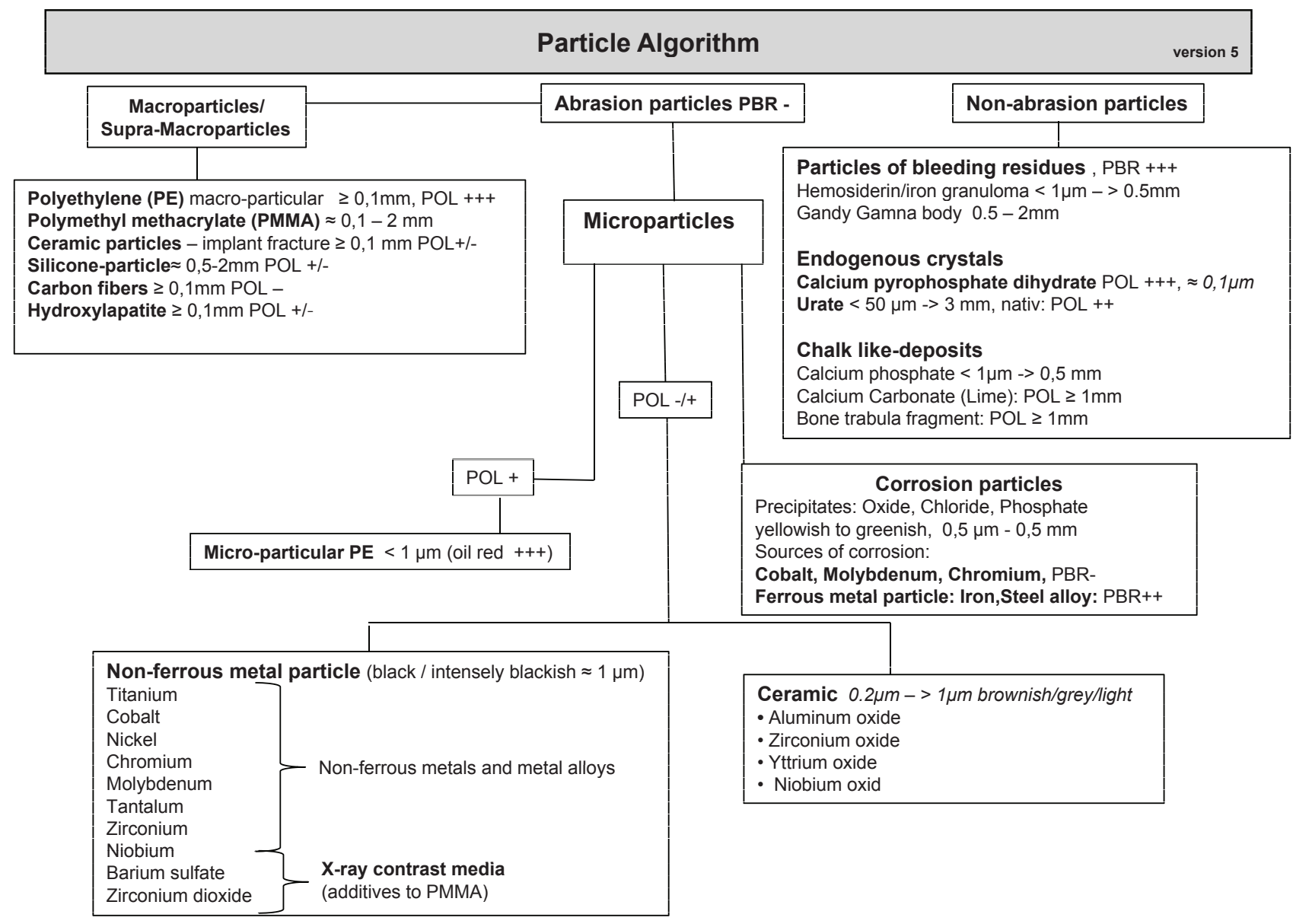

DIAGRAM 1:

Histopathological particle algorithm (version 5 after Krenn)

The particles in the SLIM are characterized in conventionally stained HE paraffin sections with the use of 1) polarization-optical analysis (POL), 2) Prussian blue reaction (PBR) and/or 3) oil red $\mathrm{O}$ staining

Definition of particle. The term particle in this histopathological context defines lightmicroscopically small anorganic/organic granula like structures with intra- or extracellular localisation detected in the SLIM.

Prosthesis material particles, non-prosthesis particles and third body wear particles. Prosthesis material particles include materials from the prosthesis itself, material from periprosthetic compartment (f.e. Hydroxylapatite, PMMA) and in cases of endoprothesis revision materials from the former prosthesis (third body wear).

Non-prosthesis particles (endogenous particles) are organic and understood to mean particles which have been produced endogenously in the synovial membrane,cartilage und bonemostly dueto metabolic dsyfunctions: Calcium pyrophosphate, urate crystals, haemosiderin deposits as the consequences of hemorrhage, calcifications and by fragmented joint tissues (cartilage and bone fragments).

\section{Definition of particle size}

Microparticles, macroparticles and supramacroparticles. The particle sizes were determined in this analysis using computer-aided interactive morphometric analysis (Leica DM 2005, microsystems framework 2007). The majority of particle size measurements are based on animal testing data [32]. For reasons of histopathological practicality, it is proposed to distinguish between 1) microparticles (phaghocytosed in macrophages, $\leq 5 \mu \mathrm{m})$ 2) macroparticles (phaghocytosed in multinucleated giant cells and/or in extracellular localisation, $\geq 5 \mu \mathrm{m}$ to $1 \mathrm{~mm}$ ) and 3) supramacroparticles being defined as particles exclusively in extracellular localisation with more $1 \mathrm{~mm}$ up to several $\mathrm{mm}$.

Morphological definition and validation of particle morphology in the SLIM. To provide a representative view of the most important particles, a total of 120 
endoprosthesis pathological cases were analyzed. These cases included the clinical data, the type of endoprosthesis and the composition of the endoprosthesis material. In order to guarantee good clarity of the morphology the different particles were shown to the same scale of the particles in the synovial membrane/SLIM. The microscopic view (Figs. 2a to 6) is shown under the same magnification and, in most cases, under the same conditions (HE staining, simple transmitted light analysis, POL analysis and oil red $\mathrm{O}$ staining).

\section{Patient data}

In SLIM cases, the particles were characterized/ validated as part of the histopathological diagnostic process. Tissue from a total of 120 cases, 75 of them women and 45 men, was analyzed. The average age was 66 . In 50 cases, the synovial membrane/SLIM was from hip endoprostheses and in 66 cases from knee endoprostheses. In four cases, the SLIM was from an ankle joint endoprosthesis and in one case from a shoulder endoprosthesis. Average prosthesis life was 7.2 years. The material composition and the implantation mode of the endoprostheses were known in all cases. The material composition covered the complete material spectrum (metal, plastic and ceramics). Bacterial infections were ruled out by histopathology and microbiology.

\section{Prussian blue reaction, $\mathrm{HE}$ staining, oil red $O$ staining}

The Prussian blue reaction and HE staining were carried out fully automatically using the Leica ST 4040 staining module. The nuclear staining was undertaken with Harris hematoxylin (Harris hematoxylin, Surgipath, Richmond, Illinois, USA). The background staining was performed using eosin (eosin Y, SigmaAldrich, St. Louis, Missouri, USA). Oil red O staining carried out exclusively non-automated in line with the published staining protocol [20].

\section{Results}

\section{Bone cement, polymethyl methacrylate (PMMA)}

Histopathologic particle morphology: Bone cement is a polymer (polymethyl methacrylate, PMMA). In the conventional histological tissue preparation, PMMA particles are mostly chemically dissolved out of the SLIM. The non dissolved out particles are pale, gray-colored rectangular. Therefore in the HE section remains a light graycolored internal structure in an apparently empty, mostly rectangular to polycyclical, vacuolelike cavity [43]. This vacuole-like cavity is surrounded by macrophages, histiocytic cells and multinucleated giant cells (Fig. 2b).

\section{Zirconium oxide/barium sulfate particles as bone cement (PMMA) additives}

Histopathologic particle morphology: They are visible mainly in the vacuoles of the PMMA (PMMA, which has been partially dissolved out) as grey to intensely black, aciniform to mullbery like [43] and in part coarse microparticulate deposits (Fig. 2b, 3f) . A light microscopic differentiation of barium sulfate and zirconium oxide is not possible. The addition of zirconium oxide or barium sulfate serves as an X-ray marker.

\section{Polyethylene (PE) particles}

$P E$ microparticles, $P E$ macroparticles and $P E$ supra-macroparticles. Histopathologic particle morphology: Depending on the particle size, a new light microscopic categorisation of $\mathrm{PE}$ particle is proposed: $\mathrm{PE}$ microparticles $(<5 \mu \mathrm{m}), \mathrm{PE}$ macroparticles ( $>5 \mu \mathrm{m}$ up to $1 \mathrm{~mm}$ ) and supra-PEmacroparticles ( $>1 \mathrm{~mm}$ up to several $\mathrm{mm}$ ) with an exclusive extracellular localisation. The supra-PEmacroparticles are shown in this paper for the very first time (Fig. 2a). This finding requires further research. An exclusive extracellular localization is plausible since due to the large size, an intracellular localization even in histocytic multinucleated giant cells is not possible. Depending on the mechanical prosthesis loading (e.g. misalignment of the implant) they are elongated and clasp-shaped and conspicuous under light microscopy [43]. What are noticeable are the polarization-optically birefringent, clasp-shaped $\mathrm{PE}$ macroparticles in multinucleated giant cells of the foreign body type (Fig. 2a). In HE staining PE microparticles are inconspicuous and can be detected in the macrophages due to a granular, slightly basophilic, cytoplasmic reactivity (Fig. 3a).

Enzyme histochemical particle characteristics: Oil red $O$ staining $[20,43]$ with an intense orange-red colour permits the clear detection of intracytoplasmic usually unsusceptible PE microparticles (Fig. 3b).

\section{Metal particles (non ferrous metal particles)}

Histopathologic particle morphology: The intrinsic color is gray to intensely black (Figs. 3c, 3d). Metal particles exhibit no, or only minimal, peripheral birefringence. The shape of the metal particles varies in the SLIM from round to polygonal and sharp-edged.

Enzyme histochemical particle characteristics: Since they are non ferrous metals the Prussian blue reaction is negative. Non-ferrous metals and their alloys are used predominantly in endoprosthetics, while ferrous metals (e.g. steel) are used more rarely. The most important non-ferrous metals include titanium, tantalum, aluminum, vanadium, cobalt, 
molybdenum, chromium, niobium and nickel in varying combinations and alloys. Metal particles are very small if they are not present in the SLIM in aggregated form, and have an average diameter of approximately $0.05 \mu \mathrm{m}$ to $3.9 \mu \mathrm{m}$ [32]. Due to their small diameter, metal particles can penetrate into the superficial and deep compartments of the SLIM as well as into the peri-implant tissue and thus be capable of detection. In rare cases, metal particles can also be detected in the regional lymph nodes [3].

\section{Metal corrosion: metal corrosion microparticles and macroparticles}

Histopathologic particle morphology: Solid corrosion products of cobalt-chromiummolybdenum alloys consist, for example, of chromium orthophosphate [23]. Depending on the metal, corrosion products can be detected as oxides, chlorides or phosphates. The colour is highly variable ranging from yellowish to greenish in as well as bluish-purple (Fig. 4a). Corrosion products (corrosion particles) are variable in size $(<1 \mu \mathrm{m}$ to $500 \mu \mathrm{m})$. Chromium orthophosphate macroparticles are demarcated from foreign body giant cells. Corrosion particles are found not only in the immediate vicinity of the metal wear but can also be detected in granulomas (Fig. 4b). Microparticles can be detected intracytoplasmically in mononucleated macrophages, occasionally mixed with metal wear particles [23]. Only steel corrosion products exhibit positive reactivity in the Prussian blue reaction. Metal corrosion can be generally defined as the destructive attack of a metal through interaction with its tissue-environment. In hip endoprostheses, modular prosthesis taper connections (e.g. neckhead or neck-stem connection) and metal-onmetal bearing couples constitute a fundamental source of corrosion/fretting. The frequency and clinical relevance of the corrosion problem have not been sufficiently investigated. During corrosion processes in connection with metal implants, alloy components are released that can be detected in the joint, in the peri-implant tissue and in bodily fluids and here involve the risk of undesirable local tissue reactions and premature implant failure as well as systemic side effects [14, 18, 34, 40, 56, 57]. Allergic reactions to metallic implant materials are described [50, 51, 52]. Corrosion products may encourage third body wear and lead to premature implant failure [23]. Corrosion products in the SLIM may be the expression of the reduced resistance of the endoprosthesis material or a mechanical overloading. There is a correlation with the design, positioning and loading of the endoprostheses.

\section{Metal ions}

Histopathologic particle morphology: Because of their small size, metal ions elude histopathological detection. Metal ions can only be detected using physical methods [31]. Weak cytoplasmic Prussian blue reactivity in the macrophages in the SLIM often in the vicinity of metal particle deposits may possibly be a cellular mode of reaction to a large metal ion load (personal observation of V. Krenn). In hip endoprosthetics, increased metal ion values (chromium, cobalt) have been detected in the blood serum and whole blood of patients with metal-onmetal bearing couples, these have been associated with persistent pains, local tissue reactions and premature implant failure [10, 19, 21].

\section{Ceramic: microparticles and macroparticles}

Histopathologic particle morphology: Particle size is variable. Ceramic particles occur in the size range of $20-100 \mathrm{~nm}$ up to $3.9 \mu \mathrm{m}$ [32]. In the rare case of prosthesis fracture of a ceramic component, macroparticles of a size of up to a few $\mathrm{mm}$ are detectable in the SLIM (Fig. 2c). A definitive detection is carried out using highresolution scanning electron microscopy (e.g. FEG-SEM) or transmission electron microscopy (TEM). Microparticles exhibit a weak to very weak polarization-optical birefringence, are variable in color, mostly yellowish-brownish or gray-brown to blackish (Fig. 3e). Especially where they appear gray-black in color, the color and the diameter of the particles hamper the histopathological demarcation of metal particles. Here physical techniques, for example energy dispersive X-ray (EDX) and/or Fourier transform infrared microspectroscopy (FTIR), are indicated for definitive particle identification [31]. In hip endoprosthetics, ceramic is used in ceramic-on-polyethylene or ceramic-on-ceramic bearing couples. In most cases, ceramic implants consist of aluminum oxide ceramic $\left(\mathrm{Al}_{2} \mathrm{O}_{3}\right)$, zirconium oxide ceramic $\left(\mathrm{ZrO}_{2}\right)$ or mixed oxide ceramic containing other components such as yttrium oxide $\left(\mathrm{Y}_{2} \mathrm{O}_{3}\right)$, strontium oxide $(\mathrm{SrO})$ or chromium oxide [35]. A pathogenic reaction to ceramic particles is unlikely. In case reports, where there are adverse reactions to metal components of hip implants, a significant improvement in the symptoms and falling metal ion levels following revisions using metal-free materials (ceramics, highly cross-linked polyethylene, polyethylene) are described in the area of bearing couples [ 1 , $12,13,14,18,21,25,26,27,37,39,45,46,47$, $57,58]$. 


\section{ILLUSTRATIONS:}

For simplifying the aspect of histological particle identification, all illustrations are shown in identical magnification and under following conditions: HE staining in simple transmitted light analysis, POL analysis and oil red $\mathrm{O}$ staining.

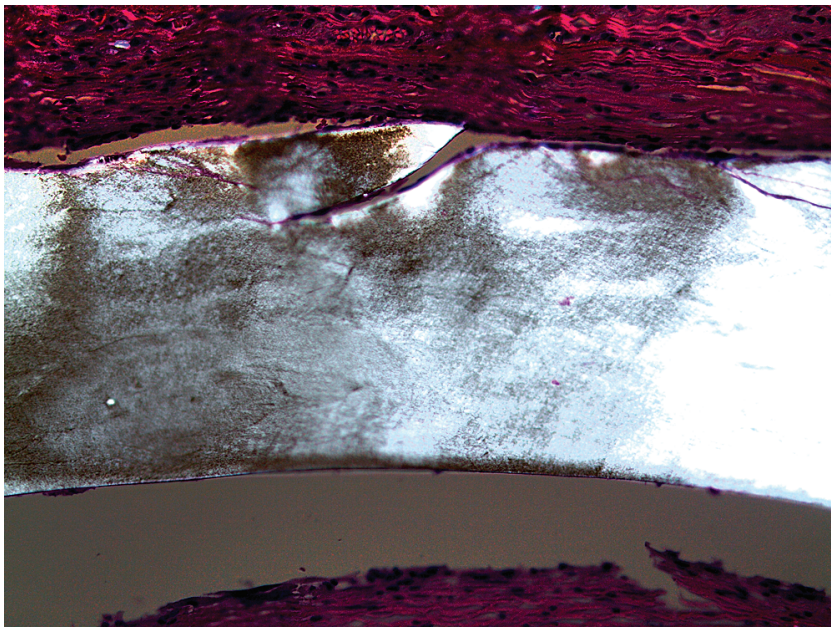

Fig. 2a. Polyethylene (PE) supra-macroparticles in POL analysis: Particles are morphologically characterized as white to yellow, bright, clasp-shaped, polarization-optically strong birefringen particles in extracellular localisation with a size of more than $1 \mathrm{~mm}$. In this case a supra-macroparticle (about $3 \mathrm{~mm}$ in lenght) in a SLIM of type I is shown. Original magnification $350 \mathrm{x}$. HE staining, POL analysis

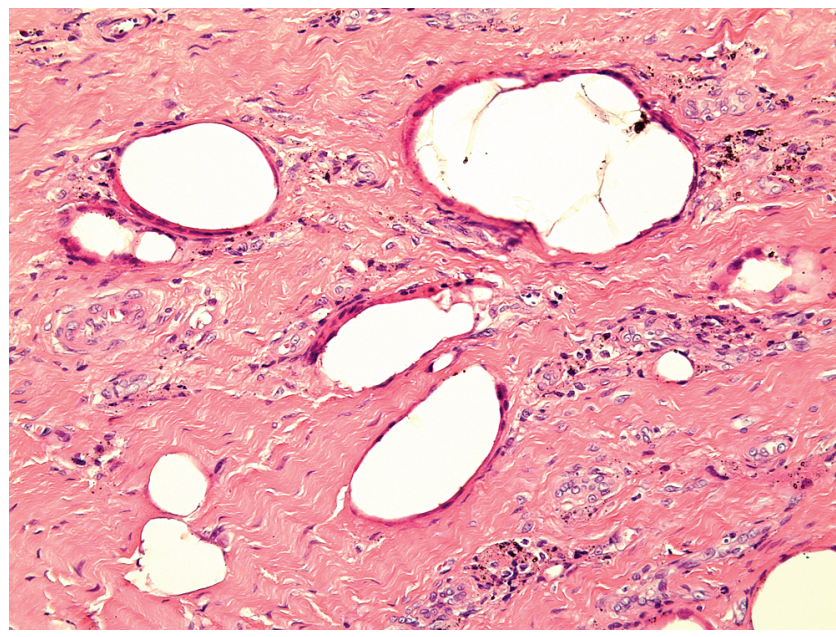

Fig. 2b. Polymethyl methacrylate, PMMA macroparticles: Particles are morphologically characterized as mainly empty (chemically dissolved out) oval to polycyclical, vacuole-like cavities in cytoplasms of multinucleated giant cells. The bone cement additives, barium sulfate and/or zirconium oxide (X-ray contrast media), may be directly visible in the form of black, partly grouped microparticulate deposits mainly in the peripheral sections of the vacuoles (3f). Original magnification $350 \mathrm{x}$, HE staining

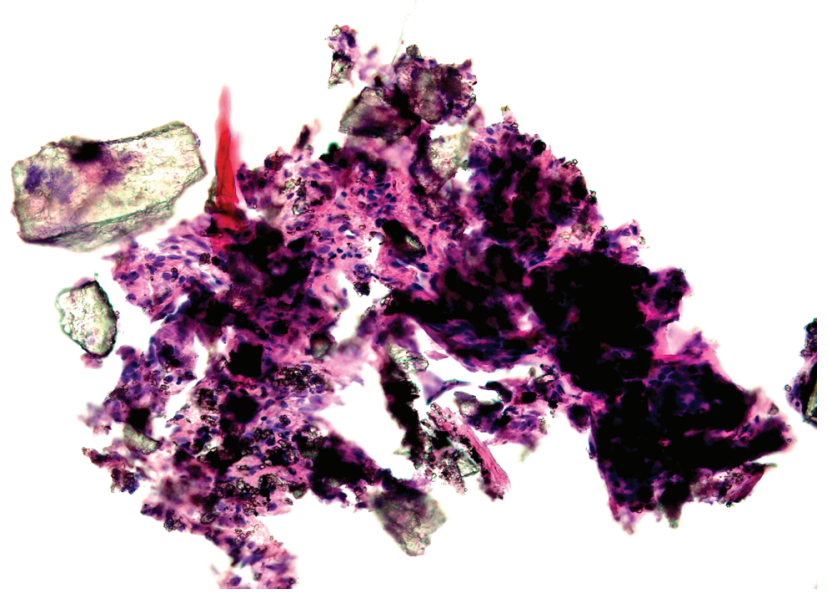

Fig. 2c. Ceramic macroparticles: Partices are morphologically characterized as dark gray-colored, rectangularly configured, extracellularly localized macroparticles. Original magnification $350 \mathrm{x}$, HE staining (case of prosthesis ceramic fracture)

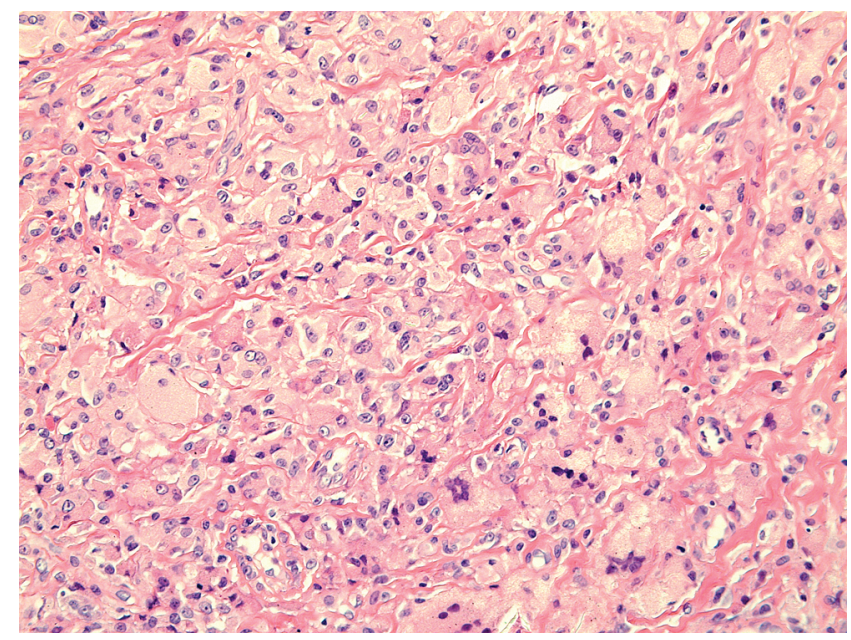

Fig. 3a. Polyethylene microparticles in HE staining, simple transmitted light analysis. Particles are morphologically characterized as microparticles localised in cytoplasm of macrophages exhibiting an inconspicuous aspect with homogeneous cytoplasmic reactivity with a slightly granular basophil/eosinophil aspect. Original magnification $350 \mathrm{x}$, HE staining 


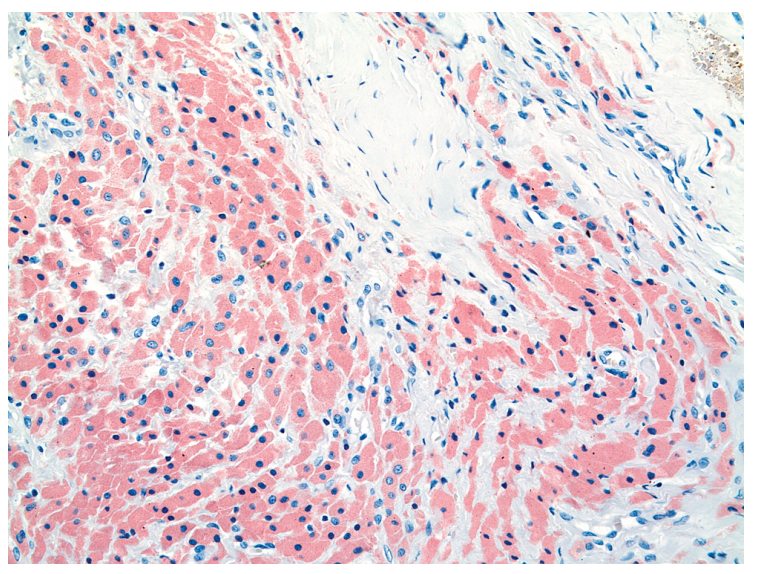

Fig. 3b. Polyethylene microparticles in oil red $\mathrm{O}$ staining: Particles are morphologically characterized in oil red

$\mathrm{O}$ staining as intensive orange-red particles located in macrophages and histiocytic cells. Original magnification $350 \mathrm{x}$, oil red O staining

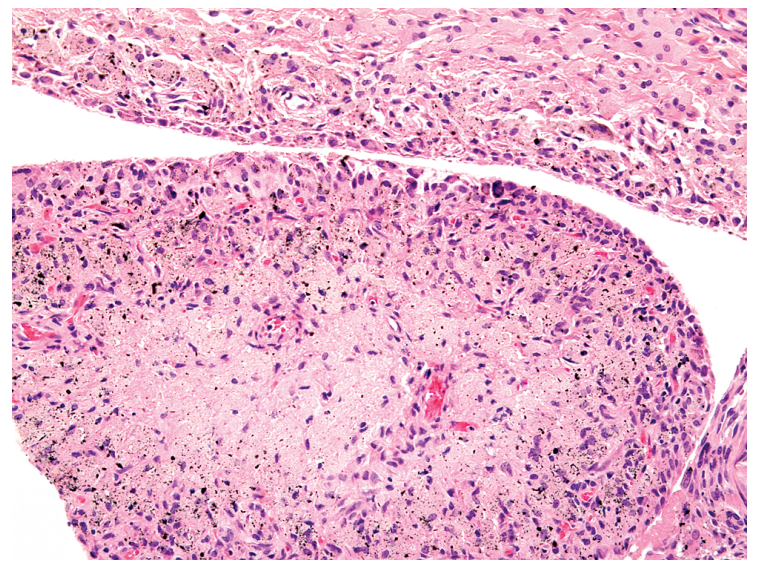

Fig. 3d. Cobalt-molybdenum-chromium microparticles: Particles are morphologically characterized as gray-black, round to polygonal, sharp-edged, mostly intracytoplasmic microparticles. Original magnification $350 \mathrm{x}$, HE staining

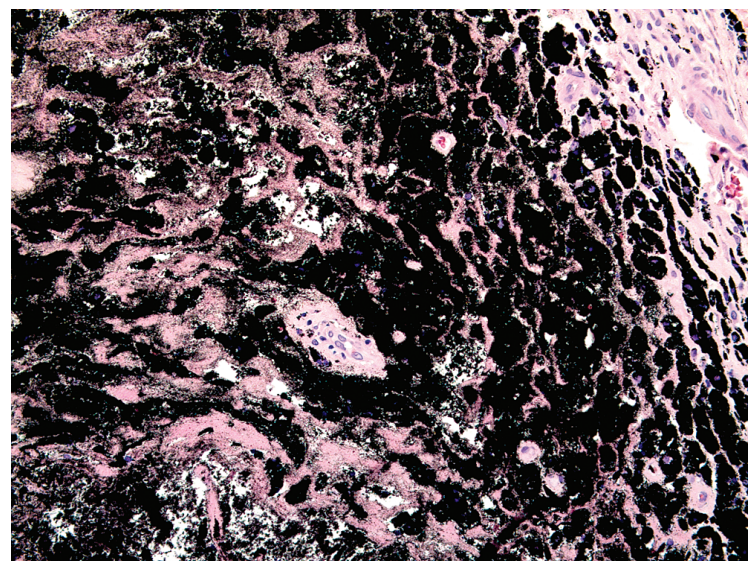

Fig. 3c. Titanium microparticles: Particles are morphologically characterized as intensely black, round to polygonal, partly isolated mostly aggregated, particles in intracytoplasmic and/or extracytoplasmic localisation. Original magnification $350 \mathrm{x}$, HE staining

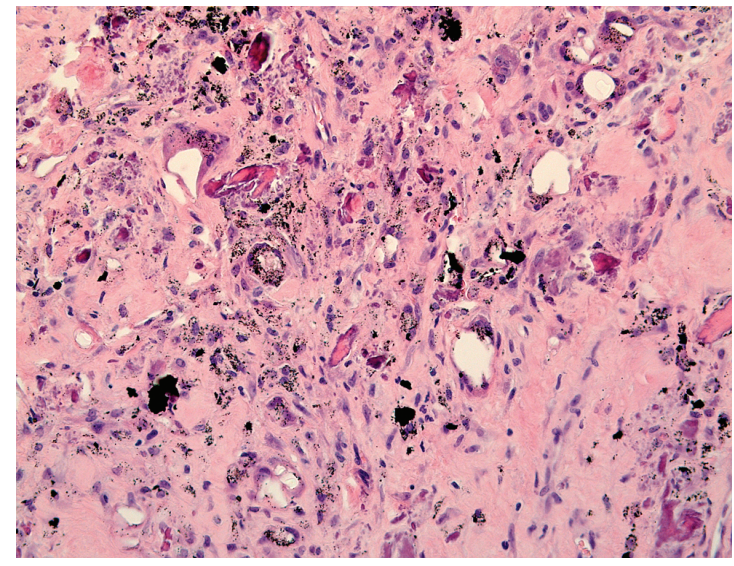

Fig. 3e. Ceramic microparticles: Particles are morphologically characterized as brownish to blackish, round to polygonal or rectangular intracytoplasmic particles. Mixed in fragments of bone trabecular. Original magnification $350 \mathrm{x}$, HE staining.

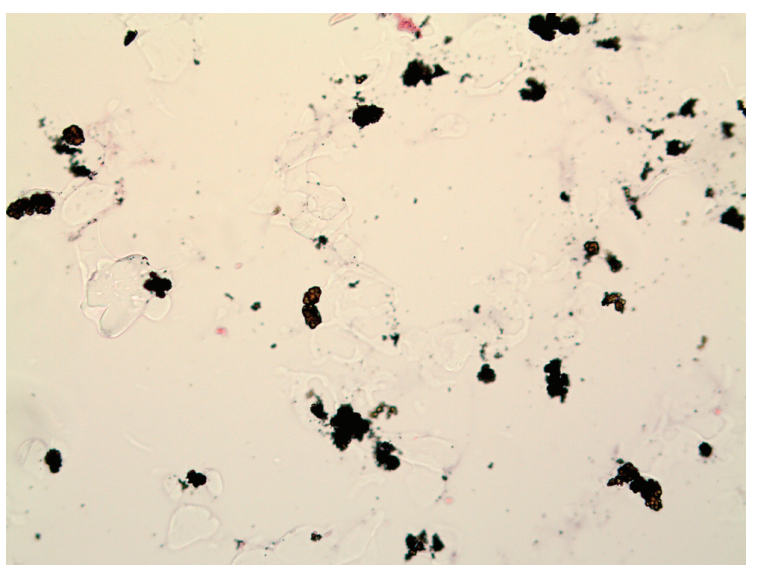

Fig. 3f. Barium sulfate and/or zirconium oxide microparticles:

Particles are morphologically characterized as grey to intensely black, aciniform-aggregates. Microparticulate deposits are mostly in dissolved out PMMA vacuoles or attached to PMMA remnants. Barium sulfate and/or zirconium oxide are bone cement additives a discrimination between Barium sulfate and zirconium oxide is not possible by light microscopy. Original magnification $350 \mathrm{x}$, HE staining 


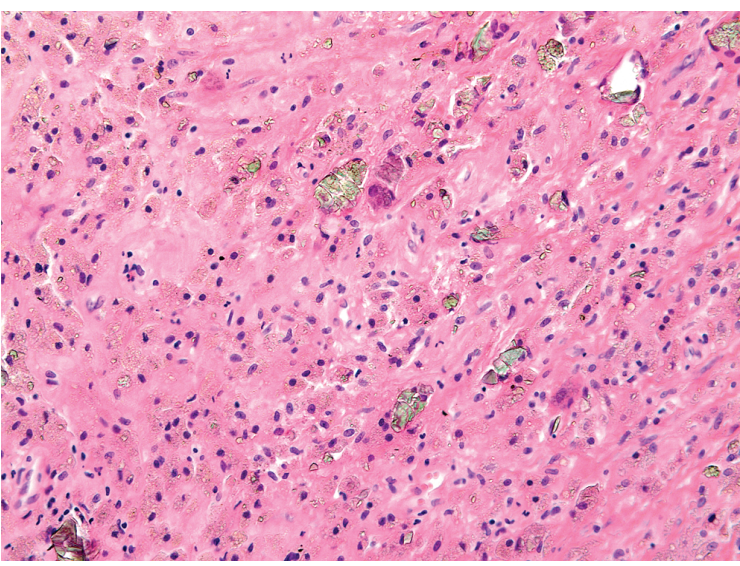

Fig. 4a. Corrosion particles: Chromium orthophosphate macroparticles: Particles are morphologically characterized as rectangular yellowish-green deposits mainly in extracellular localization. Original magnification $350 \mathrm{x}$, HE staining

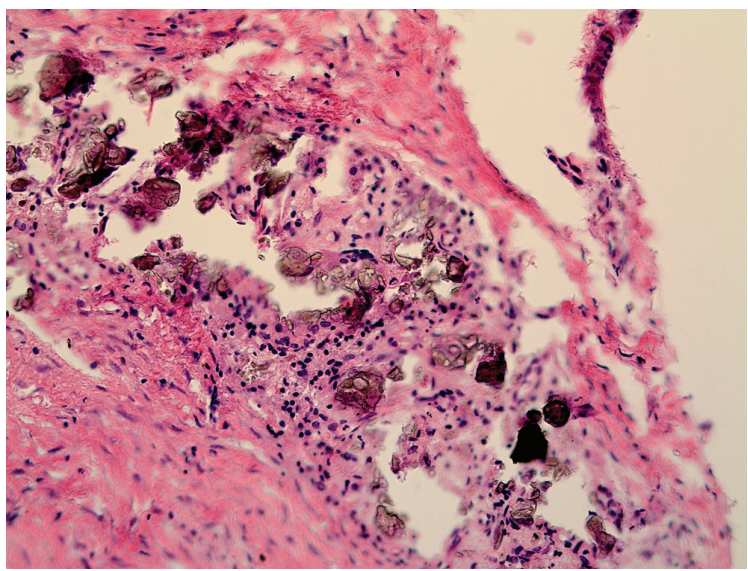

Fig. 5a. Silicone particles: Particles are morphologically characterized as pale, slight yellow to white particles with round to oval morphology partly located in polycyclical, vacuole-like cavities resembling dissolved out Silicone. Original magnification $350 \mathrm{x}$, HE staining

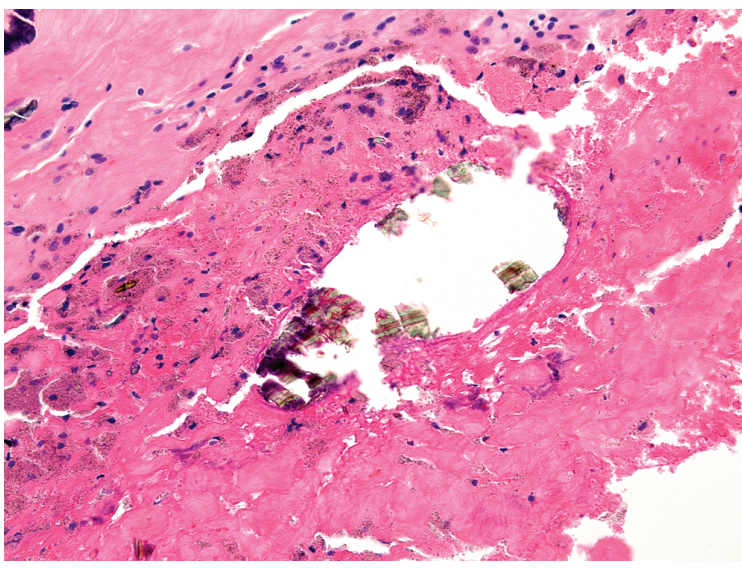

Fig. 4b. Corrosion particles: Chromium orthophosphate microparticles and macroparticles in type I SLIM located in respectively near to a necrosis. Original magnification $350 \mathrm{x}$, HE staining

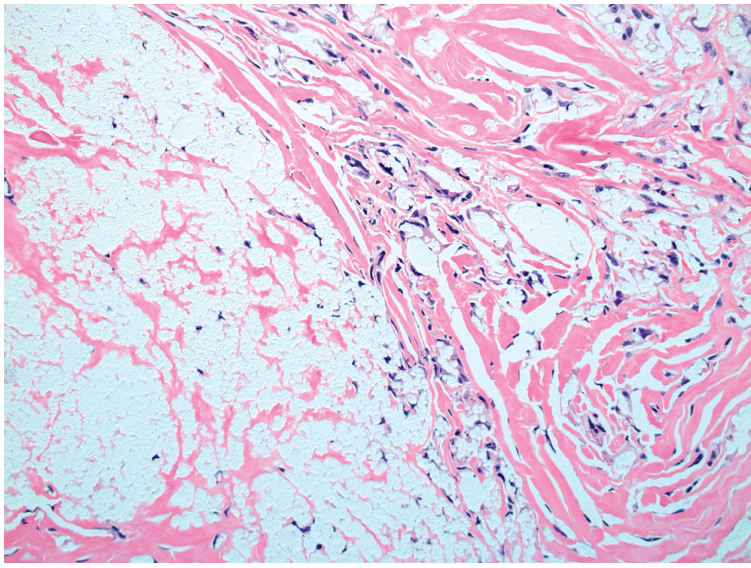

Fig. 5b. Hydroxylapatite (HA) particles: Particles are morphologically characterized as grey to darke macroparticles partially dissolved out and characterized

by non-polarization-optically birefringent property. Original magnification $350 \mathrm{x}$, HE staining

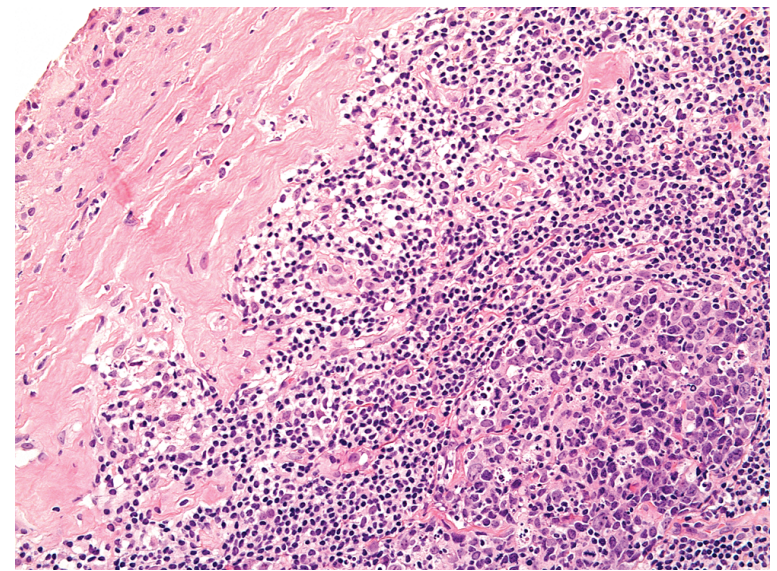

Fig. 6. A histopathological definite cases of an inflammatory pseudotumor

(SLIM Type I with predominating necrosis) in a dysfunctional metal-on-metal bearing couple (cobalt-chromium-molybdenum alloy) exhibiting focal necrotic tissue with reactive lymphocytosis (germinal center like structure). Original magnification $350 \mathrm{x}$, HE staining 


\section{Silicone particles}

Histopathologic particle morphology: These macroparticles (up to $1 \mathrm{~mm}$ ) are pale, slight yellow to white in colour with round to oval morphology and may be located in polycyclical, vacuole-like cavities resembling dissolved out Silicone-fragments (Fig. 5a). Silicone particles exhibit polarization-optically non- to variable -birefringent property. In so-called silicone synovitis [48], intrasynovial or intracapsular, polycyclical, partly rectangular macroparticles are constantly detected.

\section{Hydroxylapatite (HA)}

Histopathologic particle morphology: These micro- to macroparticles are light to dark, grey to black in color (Fig. 5b) partially dissolved out and characterized by a non- polarization-optically birefringent property. Hydroxylapatite is a bonelike calcium phosphate compound. The HA coating facilitates the rapid osseointegration of the endoprosthesis. Hydroxylapatite is fully replaced by the periprosthetic bone formation and can only be detected by hard grinding techniques [23] or in very early phases following implantation (Fig. 5b).

\section{Endogenous particles}

Gout is the pathogenetically best understood crystal arthropathy in which monosodium urate crystals deposits develope mostly in connective articular and extra articular tissues (17). These cristal deposits are located under native conditions intracellular. In HE stained sections they are predominately chemically dissolved out and intacytoplasmic needle shaped structures, as remnants, embedded in a homogenous basophilic matrix are detectable. Calcium pyrophosphate dihydrate (CPPD) depositions are polarizationoptically birefringent cuboid like particles which are characteristically embedded in a dark brownish matrix and are in HE stained sections directly detectable (17). Basic calcium phosphate and calcium pyrophosphate dihydrate are characterised as blue homogenous deposits and are not polarization-optically birefringent (17).

\section{Discussion}

\section{Particle identification in the SLIM by the histopathological particle algorithm}

In general algorithms, as defined procedures for solving a diagnostic or therapeutic problem. Diagnostic algorithms are prevalent and widely used in guideline-oriented medical science. A histopathological particle algorithm based on particle-defining criteria is proposed $[7,8,9,19$, $20,22,23,24,32,35,36,60]$ that based on routine histopathological techniques, offers a guide to particle identification in the SLIM. The particle qualities described have been corroborated by the analysis of 120 clinically defined joint pathological cases and a light microscopic categorisation of particle size is proposed. The particle algorithm also makes it possible to differentiate between nonprosthesis material particles and prosthesis material particles. The characterization of the particles is defined in a graduated manner (non-prosthesis material particles, prosthesis material particles) in accordance with a dichotomous principle based on staining characteristics, polarization-optical properties and particle size. This is illustrated graphically in the flow chart (Diagram 1).

The particle algorithm is designed to assist the non-specialist pathologist, orthopedist, orthopedist working in an experimental capacity and materials scientist to identify particulate material in the SLIM with minimal methodical complexity with standard histopathological techniques.

It is relevant to notice hat histopathological particle identification, particularly in metallic and ceramic materials, constitutes a guide to identification. Definitive, physical material identification, particularly of metallic and ceramic wear particles, is only possible through the use of physical, high-resolution procedures, for example energy dispersive X-ray (EDX) and/or Fourier transform infrared microspectroscopy (FTIR) [30].

\section{Particle-associated reaction patterns in the SLIM}

Particle-induced reactions as well as immunological and toxic changes in the SLIM are influenced by the particle quality (material, size, and surface) and quantity, the type of tissue and cells involved by the particulate material and probably genetic factors influencing the immunological or inflammatoric response. As an assessment of the tissue reaction pattern (inflammatory reaction pattern) should also accompany the histopathological particle identification for logical reasons, the most important particle reaction patterns in the SLIM are shown. Due to developments in materials and designs in endoprosthetics [3, 6, 57], new types of particles and reaction patterns [5, 11, $14,34]$ are constantly arising in the SLIM. These histopathological reaction patterns are determined by prosthesis design, the positioning and loading of the endoprosthesis, particle quality and quantity, oportunities for tissue and cellular particle permeation [23, 24, 31]. 


\section{Wear particle-induced necroses in the SLIM}

Pronounced wear particle deposition of metallic and non-metallic materials are associated with wear-induced necroses (aseptic necroses) may be detectable, especially in type I SLIM [7, 20, 43]. Etiologically speaking, a toxic effect in the sense of a particle overloading of the tissue is discussed [43]. Using oil red O staining, PE microparticles, for example, can be shown in the necroses [20, 43]. The differentiation of wear particle-induced granulomas from granulomas in mycobacteriosis may require a PCR-based pathogen clarification [28]. Solid corrosion products of cobalt-chromiummolybdenum alloys [31] consist, for example, of chromium orthophosphate [23]. In the literature, corrosion phenomena in connection with metal implants are again being described more frequently $[2,13,14,21,23,40]$. The occurrence of corrosion products in the SLIM may also be associated with a granulomatous inflammatory reaction [23].

\section{SLIM-reaction patterns in dysfunctional metal-on-metal bearing couples}

In hip endoprostheses with dysfunctional metal-on-metal bearing couples, reduced service lives have been described [19, 36, 39]. In the typical pathological cases of metal-on-metal bearing often subtotal necroses and macrophage infiltrates (containing intracytoplasmic micro-metal particles), pronounced lymphocytic, partially also lymphofollicular inflammatory infiltrates have also been detected [36]. The pathological changes are not constant. Obviously, as already described in the case of corrosion processes [13, 18, 23, 34], there is a correlation with the composition of the material, with non-physiological force transmission (e.g. large head diameter, misalignments) and with the degree of activity of the patient. As a result of tissue interfoldings of the subtotally necrotic tissue, granuloma-like structures develop, conspicuous in dysfunctional metal-on-metal bearing couples and corrosion phenomena, that are described clinically as an inflammatory pseudotumor (Fig. 6) [36]. The pathogenesis of the necrotic-lymphocytic pattern and inflammatory pseudotumor is not fully clarified. Causally, besides direct toxicity due to metal particles in the sense of an overloading of the tissue with microparticles, a cell-mediated, delayed type IV hypersensitivity reaction on components of metal implants is discussed, in which metal-reactive T-lymphocytes have a key pathogenetic role $[51,52,53]$. In the literature, patients provided with endoprosthetics who have conspicuous symptoms and a proven implant material allergy are recommended to switch to ceramic or surface-treated implants (e.g. nitrides, oxynitrides) [51], as they offer outstanding biological conditions. In the case of adverse reactions to components of metal implants, an improvement in the symptoms and falling metal ion concentrations in the blood following revision surgery using metal-free materials (ceramics, highly cross-linked polyethylene, polyethylene) in hip endoprosthetics $[1,12,13,14,18,21,25,26$, 27, 37, 39, 45, 46, 47, 57, 58], and non-sensitive metallic materials (surface-treated implants) and ceramics in knee endoprosthetics $[3,5,6,17,44$, $49,51,53,55]$, have been described.

\section{Histopathologic particle score (HPS)}

Since in SLIM diagnostic apart from infection diagnosis, particle identification and particleassociated reaction patterns is crucial, a summary assessment is advisable. The histopathologic particle score (HPS) should summarize, in an abbreviated form, the most relevant information for the orthopedist/material scientist including: Dominating prosthesis particle material (size: micro-particulate, macro- particulate, supramacro-particulate and material-specification), non-prosthesis particle material (present, not present, and specification), the inflammatory reaction pattern (necroses, including guideline area data in percent), and lymphocytic infiltrates/epitheloid cell reactions, granuloma formation (present, not present).

\section{Conclusions}

The heterogeneity of endogenous crystalline , crystallinelikedeposits(f.e.Calciumpyrophosphate dihydrate, monosodium urate crystals) and particulate prosthesis material deposits in the SLIM, the wide variety of endoprosthesis materials and the diversity of material combinations and variability of particle pathogenesis mechanisms explain the high degree of morphological particle heterogeneity in the SLIM. This hampers diagnostic particle identification. Therefore a histopathological particle algorithm (HPS) has been developed that, with minimal methodical complexity, offers a guide to particle identification and a means of differentiation from non-prosthesis material particles. What is proposed is a summary assessment (particle score) for diagnostics that, in an abbreviated form, summarizes the most important information for material scientist and the orthopedist. Based on this, a differential diagnosis of inflammatory changes in the synovial membrane/SLIM is possible. Due to advancing developments in implant materials in endoprosthetics, a web-based particle algorithm is desirable. This web-based particle algorithm could guarantee constant updating of the particle identification and inflammatory reaction pattern allowing definite particle diagnostic in the SLIM. 


\section{Conflict of interest}

One female and one male author ${ }^{5}$ are part of the Science Department at CeramTec GmbH, not with standing a possible conflict of interest, this scientific article is scientific independent and product-neutral.

In histopathologic SLIM diagnostic (synovial-like interface membrane, SLIM) apart from diagnosing periprosthetic infection particle identification has an important role to play. The differences in particle pathogenesis and variability of materials in endoprosthetics explain the particle heterogeneity that hampers the diagnostic identification of particles. For this reason, a histopathological particle algorithm has been developed. With minimal methodical complexity this histopathological particle algorithm offers a guide to prosthesis material-particle identification. Light microscopic-morphological as well as enzyme-histochemical characteristics and polarization-optical proporties have set and particles are defined by size (microparticles, macroparticles and supra- macroparticles) and definitely characterized in accordance with a dichotomous principle. Based on these criteria, identification and validation of the particles was carried out in 120 joint endoprosthesis pathological cases. A histopathological particle score (HPS) is proposed that summarizes the most important information for the orthopedist, material scientist and histopathologist concerning particle identification in the SLIM.

\section{Literature}

1. Algarni A.D., Huk O.L., Pelmus M. Metallosis-induced iliopsoas bursal cyst causing venous obstruction and lower-limb swelling after metal-on-metal THA. Orthopedics. 2012;35(12):1066-1069.

2. Asencio G., Essig J., Nourissat Ch., Caremeau C. Abnormal local tissue reaction after total hip arthroplasty with a modular $\mathrm{Co}-\mathrm{Cr}$ femoral piece. SOFCOT, Abstract 269, 2011.

3. Bader R., Bergschmidt P., Fritsche A., Ansorge S., Thomas P., Mittelmeier W. Alternative Werkstoffe und Lösungen in der Knieendoprothetik für Patienten mit Metallallergie [Alternative materials and solutions in total knee arthroplasty for patients with metal allergy]. Orthopäde. 2008;37(2):136-142.

4. Bader R., Mittelmeier W., Steinhauser E. Versagensanalysevon Knieendoprothesen:Grundlagen und methodische Ansätze zur Schadensanalyse [Failure analysis of total knee replacement. Basics and methodological aspects of the damage analysis]. Orthopäde. 2006;35(9): 896-903.

5. Bergschmidt P., Bader R., Mittelmeier W. Metal hypersensitivity in total knee arthroplasty: Revision surgery using a ceramic femoral component - A case report. Knee. 2012;19:144-147.

6. Bergschmidt P., Bader R., Kluess D., Zietz C. Mittelmeier W. the all-ceramic knee endoprosthesis the gap between expectation and experience with ceramic implants. Semin Arthro. 2012;23(4):262-267.

7. Bertz S., Kriegsmann J., Eckardt A., Delank K., Drees
P., Hansen T., Otto M. Correlation of quantitative histopathological morphology and quantitative radiological analysis during aseptic loosening of hip endoprotheses. J. Appl. Biomat. Biomech. 2006;4(3):153-164.

8. Bos I. Gewebereaktionen um gelockerte Hüftgelenksendoprothesen. Eine histologische Studie an Sekundärkapseln und Interfacemembranen [Tissue reactions around loosend hip joint endoprostheses. A histological study of secondary capsules and interface membranes]. Orthopäde. 2001;30(11):881-889.

9. Bos I., Berner J., Diebold J., Löhrs U. Histologische und morphometrische Untersuchungen an Femora mit stabilen Hüftgelenksendoprothesen. Z. Orthop. 1995; 133:460-466.

10. Bosch U., Zeichen J., Skutek M., Haeder L., van Griensven. Arthrofibrosis is the result of a $\mathrm{T}$ cell mediated immune response. Knee Surg. Sports Traumatol. Arthrosc. 2011;9(5):282-289.

11. Campbell P., Ma S., Yeom B., McKellop H., Schmalzried T.P., Amstutz H.C. Isolation of predominantly submicron-sized UHMWPE wear particles from periprosthetic tissues. J. Biomed. Mater. Res. 1995;29(1):127-131.

12. Campbell P., Shimmin A., Walter L., Solomon M. metal sensitivity as a cause of groin pain in metal-on metal hip resurfacing. J. Arthroplasty. 2008;23(7):1080-1085.

13. Cooper H.J., Della Valle C.J., Berger R.A., Tetreault M., Paprosky W.G., Sporer S.M., Jacobs J.J. corrosion at the head-neck taper as a cause for adverse local tissue reactions after total hip arthroplasty. J. Bone Joint Surg. Am. 2012;94:1655-1661.

14. Cooper H.J., Della Valle C.J., Jacobs J.J. biologic implications of taper corrosion in total hip arthroplasty. Semin Arthro. 2012;23(4):273-278.

15. Fuerst M., Zustin J., Rüther W: Kristallarthropathien [Crystal arthropathies]. Der Pathologe. 2011;32(3):193-199.

16. Gallo J., Kolár M., Novotný R., Riháková P., Tichá V. Pathogenesis of Prosthesis-Related Infection. Biomed. Papers. 2003;147(1):27-35.

17. Gao X., He R.X., Yan S.G., Wu L.D. dermatitis associated with chromium following total knee arthroplasty. J. Arthroplasty. 2011;26(4):665.e13-e16.

18. Gill I.P.S., Webb J., Sloan K., Beaver R.J. Corrosion at the neck-stem junction as a cause of metal ion release and pseudotumour formation. J. Bone Joint Surg. Br. 2012;94:895-900.

19. Haddad F.S., Thakrar R.R., Hart A.J., Skinner J.A., Nargol A.V.F., Nolan J.F., Gill H.S., Murray D.W., Blom A.W., Case C.P. Metal-on-metal bearings. The Evidence so far. J. Bone Joint Surg. Br. 2011;93:572-579.

20. Hansen T., Otto M., Buchhorn G.H., Scharnweber D., Gaumann A., Delank K.S., Eckardt A., Willert H.G., Kriegsmann J., Kirkpatrick C.J. New aspects in the histological examination of polyethylene wear particles in failed total joint replacements. Acta Histochem. 2002;104: 263-269.

21. Harvie P., Giele H., Fang C., Ansorge O., Ostlere S., Gibbons M., Whitwell D. The treatment of femoral neuropathy due to pseudotumour caused by metal-onmetal resurfacing arthroplasty. Hip Int. 2008;18:313-320.

22. Hirakawa K., Bauer T.W., Stulberg B.N., Wilde A.H. Comparison and quantitation of wear debris of failed total hip and total knee arthroplasty. J. Biomed. Mater. 
Res. 1996;31(2): 257-263.

23. Huber M., Reinisch G., Trettenhahn G., Zweymüller K., Lintner F. Presence of corrosion products and hypersensitivity-associated reactions in periprosthetic tissue after aseptic loosening of total hip replacements with metal bearing surfaces. Acta Biomaterialia. 2009;5:172-180.

24. Jacobs J.J., Gilbert J.L., Urban R.M. Corrosion of metal orthopaedic implants. J. Bone Joint Surg. Am. 1998;80:268-282.

25. Jameson S., Ramisetty N., Langton D., Webb J., Logishetty R., Nargol A. ALVAL: Diagnosis, incidence and treatment in contemporary metal-on-metal bearings. Abstract F11, EFORT 2008.

26. Kemp M.A., Mitra A., Mendes da Costa, Spencer R.F. Bearing exchange in the management of pseudotumors. Ann. R. Coll. Surg. Engl. 2013;95:266-270.

27. Kosukegawa I., Nagoya S., Kaya M., Sasaki K., Sasaki M., Yamashita T. Revision total hip arthroplasty due to pain from hypersensitivity to cobalt-chromium in total hip arthroplasty. J. Arthroplasty. 2011;26(6):978.e1-e3.

28. Krenn V., Thomas P., Thomsen M., Kretzer J.P. et al. Histopathological particle algorithm: Particle identification in the synovia and the SLIM. Z. Rheumatol. 2014; 73(7):639-649.

29. Krenn V., Poremba C., Schneider J., Kendoff D. et al. Histopathological differential diagnostics in context of joint implant allergic reactions. Orthopade. 2013;42(8):614-621.

30. Krenn V., Kretzer J.P., Thomas P., Thomsen M. et al. Update on endoprosthesis pathology: Particle algorithm for particle identification in the SLIM, Seminars in Arthroplasty. 2013; 24(4):265-275.

31. Kretzer J.P., Zietz C., Schröder C., Reinders J., Middelborg L., Paulus A., Sonntag R., Bader R., Utzschneider S. Grundlagen zur tribologischen Analyse von Endoprothesen [Principles of tribological analysis of endoprostheses]. Orthopäde. 2012; 41(10):844-852.

32. Kubo T., Sawada K., Hirakawa K., Shimizu C., Takamatsu T., Hirasawa Y. Histiocyte reaction in rabbit femurs to UHMWPE, metal, and ceramic particles in different sizes. J. Biomed. Mater. Res. 1999;45(4):363-369.

33. Laffer R., Ruef C. Diagnose und Therapie von Gelenkprotheseninfektionen. Z. Rheumatol. 2006;65:12-17.

34. Langton D.J., Sidaginamale R., Lord J.K., Nargol A.V., Joyce T.J. Taper junction failure in large-diameter metal-on-metal bearings. Bone Joint. Res. 2012;1:56-63.

35. Lintner F., Böhm G., Huber M., Zweymüller K. Histologisch-immunhistologische, morphometrische und bakteriologische Untersuchungen des Gelenkkapselgewebes nach Reoperation totaler Hüftendoprothesen unter Verwendung der Metall/ Metallpaarung. Osteol. 2013;12: 233-246.

36. Mahendra G., Pandit H., Kliskey K., Murray D., Gill H.S., Athanasou N. Necrotic and inflammatory changes in metal-on-metal resurfacing hip arthroplasties. Acta Orthop. 2009;80(6):653-659.

37. Mao X., Tay G.H., Godbolt D.B., Crawford R.W. Pseudotumor in a well-fixed metal-on-polyethylene uncemented hip arthroplasty. J. Arthroplasty. 2012;27(3) :493.e13-e17.

38. Marculescu C.E., Berbari E.F., Cockerill F.R. 3rd, Osmon D.R. Fungi, mycobacteria, zoonotic and other organisms in prosthetic joint infection. Clin. Orthop.
2006;451:64-72.

39. Maurer-Ertl W., Friesenbichler J., Liegl-Atzwanger B. Kuerzl G., Windhager R., Leithner A. noninflammatory pseudotumor simulating venous thrombosis after metalon-metal hip resufacing. Orthopedics. 2011;34(10):678.

40. Meyer H., Mueller T., Goldau G., Chamaon K. Ruetschi M., Lohmann C.H. Corrosion at the cone/ taper interface leads to failure of large-diameter metal-on-metal total hip arthroplasties. Clin. Orthop. 2012;470(11):3101-3108.

41. Morawietz L., Classen R.A., Schröder J.H., Dynybil C., Perka C. et al. Proposal for a histopathological consensus classification of the periprosthetic interface membrane. J. Clin. Pathol. 2006;59:591-597.

42. Mortier J., Engelhardt M. Foreign body reaction in carbon fiber prosthesis implantation in the knee jointcase report and review of the literature. Z. Orthop. 2000;138(5):390-394.

43. Otto M., Kriegsmann J., Gehrke T., Bertz S. Abriebpartikel: Schlüssel der aseptischen Prothesenlockerung? [Wear particles: key to aseptic prosthetic loosening?] Pathologe. 2006;27(6):447-460.

44. Post D.Z., Orozco F.R., Ong A.C. metal sensitivity after TKA presenting with systemic dermatitis and hair loss. Orthopedics. 2013;36(4):e525-e528.

45. Rajpura A., Porter M.L., Gambhir A.K., Freemont A.J., Board T.N. Clinical experience of revision of metal on metal hip arthroplasty for aseptic lymphocyte dominated vasculitis associated lesions (ALVAL).Hip Int. 2010;21(1):43-51.

46. Scully W.F., Teeny S.M. pseudotumor associated with metal-on-polyethylene total hip arthroplasty. Orthopedics. 2013;36(5):e666-e670.

47. Shahrdar C., Campbell P., Mirra J., Dorr L.D. Painful metal-on-metal total hip arthroplasty. J. Arthroplasty. 2006;21(2):289-293.

48. Siemon B., Schubert T., Grifka J., Borisch N Ungewöhnliche Komplikation der Silikonsynovialitis am rheumatischen Handgelenk [Unusual complication of silicon synovitis in the rheumatoid wrist]. Z Rheumatol. 2004;63(3):230-234.

49. Thakur R.R., Ast M.P., McGraw M., Bostrom M.P., Rodriguez J.A., Parks M.L. Severe persistant synovitis after cobalt-chromium total knee arthroplasty requiring revision. Orthopedics. 2013; 36(4):e520-e524.

50. Thomas P., Braathen L.R., Dörig M., Auböck J., Nestle F., Werfel T., Willert H.G. Increased metal allergy in patients with failed metal-on-metal hip arthroplasty and periimplant T-lymphocytic inflammation. Allergy. 2009;64(8):1157-1165.

51. Thomas P., Schuh A., Ring J., Thomsen M. Orthopädischchirurgische Implantate und Allergien [Orthopedic surgical implants and allergies: Joint statement by the Implant Allergy Working Group (AK 20) of the DGOOC (German Association of Orthopedics and Orthopedic Surgery)]. Hautarzt. 2008;59:220-229.

52. Thomas P., Thomas M., Summer B., Dietrich K., Zauzig M., Steinhauser E., Krenn V., Arnholdt H., Flaig M.J. Impaired wound-healing, local eczema, and chronic inflammation following titanium osteosynthesis in a nickel and cobaltallergic patient: a case report and review of the literature. J. Bone Joint Surg. Am. 2011;93(11):e611-e615.

53. Thomas P., von der Helm C., Schopf C., Thomsen M., Frommelt L., Schneider J., Flaig M., Krenn V., Mazoochian F., Summer B. Periimplant histology 
and cytokine pattern in metal-allergic knee arthroplasty patients with improvement after revision with hypoallergenic materials. Semin Arthro. 2012;23(4):268-272.

54. Thomsen M., Kretzer J.P., Krenn V., Thomas P. Unterschiedliche Erscheinungsbilder bei Patienten mit Metall/Metall-Gleitpaarungs-Prothesen [Different symptoms in patients with prostheses with metal-metal bearings]. Orthopäde. 2013;42(8):637-642.

55. Thomsen M., Rozak M., Thomas P. Pain in a chromiumallergic patient with knee arthroplasty: disappearance of symptoms after revision with a special surface-coated TKA. Acta Orthop. 2011;82(3):386-388.

56. Urban R.M., Jacobs J.J., Gilbert J.L., Galante J.O. Migration of corrosion products from modular hip prostheses. J. Bone Joint Surg. Am. 1994;76:1345-1359.

57. Vundelinckx B.J., Luk A., Verhelst L.A., Schepper
J.D.Taper corrosion in modular hip prostheses analysis of serum metal ions in 19 Patients. J. Arthroplasty. 2013;28(7):1218-1222.

58. Watters T.S., Cardona D.M., Menon K.S., Vinson E.N., Bolognesi M.P., Dodd L.G.Aseptic lymphocyte-dominated vasculitis-associated lesion: a clinicopathologic review of an underrecognized cause of prosthetic failure. Am. J. Clin. Pathol. 2010;134(6):886-893.

59. Witzleb W.C., Hanisch U., Kolar N., Krummenauer F., Guenther K.P. Neo-capsule tissue reactions in metal-on-metal hip arthroplasty. Acta Orthop. 2007;78(2):211-220.

60. Wolfarth D.L., Han D.W., Bushar G., Parks N.L. Separation and characterization of polyethylene wear debris from synovial fluid and tissue samples of revised knee replacements. J. Biomed. Mater. Res. 1997;34(1):57-61

КОНТАКТНАЯ ИНФОРМАЦИЯ:

Кренн Вейт - профессор Центра гистологии, цитологии и молекулярной диагностики;

Krenn Veit-MD Professor, Center for Histology, Cytology and Molecular Diagnostics; e-mail: krenn@patho-trier.de

Рукопись поступила 08.07.2014 